\title{
OPTIMIZATION OF THE STRUCTURAL DESIGN OF ASPHALT PAVEMENTS
}

SEPTEMBER 1971 - NUMBER 18

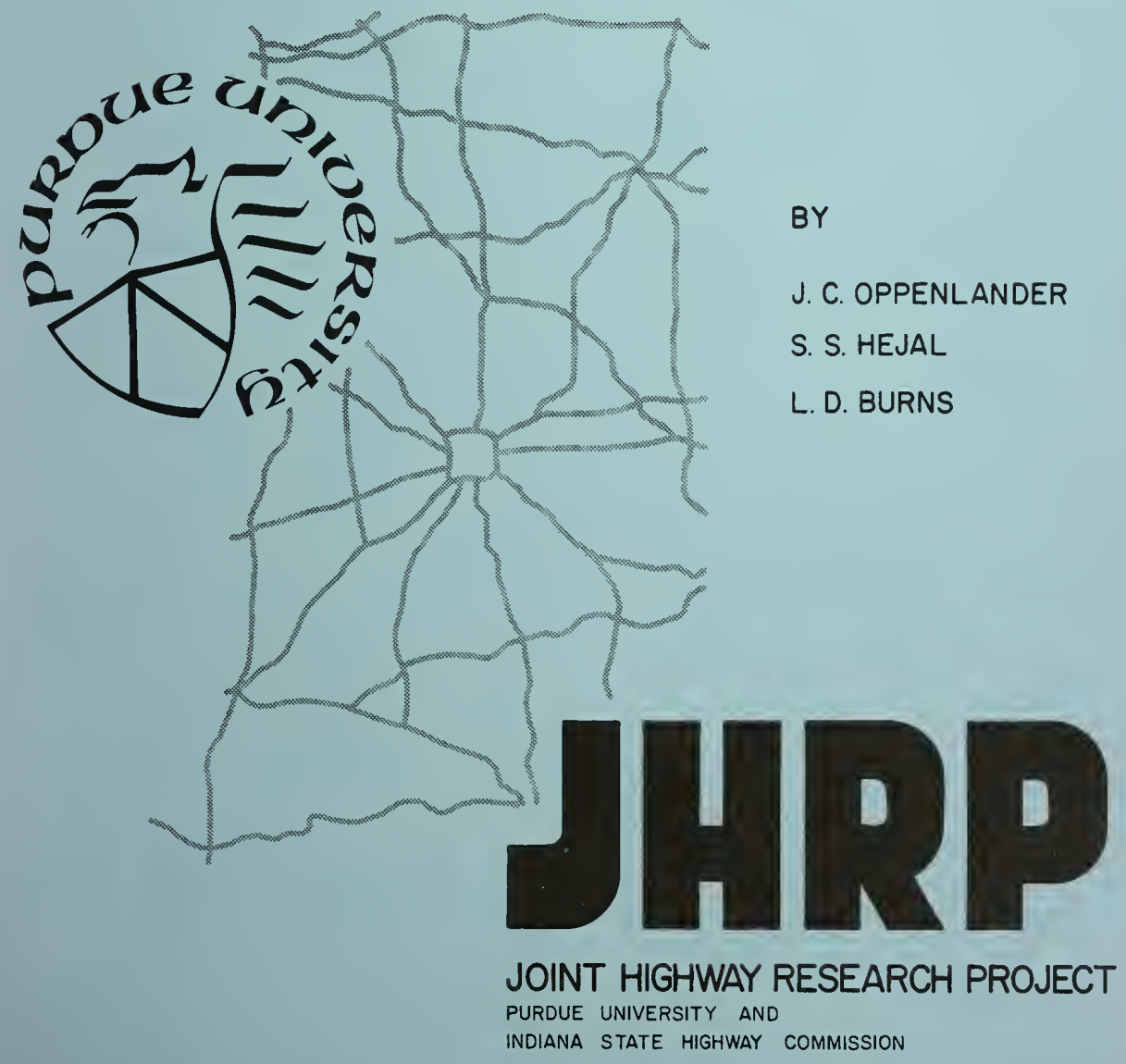



OPTIMIZATION OF THE STRUCTURAL DESIGN OF

ASPHALT PAVEMENTS

To: J. F. McLaughlin, Director

Joint Highway Research Project

FROM: H. L. Michael, Associate Director Joint Highway Research Project
September 28, 1971

Project: C-36-52I

File: $\quad 6-20-9$

The attached Technical Paper "Optimization of the Structural Design of Asphalt Pavements" has been prepared by Professor J. C. Oppenlander and Messrs. S. S. llejal and L. D. Burns. Professor Oppenlander and $\mathrm{Mr}$. Hejal conducted much of the research which resulted in this paper while members of the Project staff. The research reports containing the research have already been reported to the Board in several reports.

The paper has been prepared for publication and is submitted to the Board as information and for approval of that publication as the research on which the paper is based was Project sponsored.

The paper details a systems approach to the structural design of asphalt pavements which provides a practical and realistic method for the optimal selection of the pavement components. Substantial cost savings may result from use of the proposed design procedure.

Sincerely,

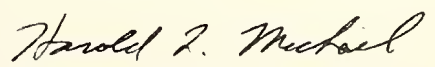

Harold L. Michael Associate Director

$H L M: m s$

cc: W. L. Dolch

W. H. Goetz

W. L. Grecco

M. J. Gutzwiller

G. K. Hallock

M. E. Harr
R. H. Harrel1

M. I. Hayes

R. D. Miles

J. W. Miller

C. F. Scholer

M. B. Scott
W. T. Spencer

J. A. Spooner

N. W. Steinkamp

H. R. J. Walsh

K. B. Woods

F. J. Yoder 
Technical Paper

OPTIMIZATION OF THE STRUCTURAL DESIGN OF

ASPHALT PAVEMENTS

by

J. C. Oppenlander

S. S. Hejal

L. D. Burns

Joint Highway Research Project

Project No.: C-36-52I

File No.: 6-20-9

\begin{abstract}
Conducted By
Joint Highway Research Project Engineering Experiment Station Purdue University

In Cooperation With

Indiana State Highway Commission
\end{abstract}

Purdue University Lafayette, Indiana

September 28,1971 
OPTIMIZATION OF THE STRUCTURAL DESIGN OF ASPHALT PAVEMENTS

J. C. Oppenlander*, S. S. Hejal** and L. D. Burns***

\section{ABSTRACT}

In general, the development of techniques for the structural design of asphalt pavements has been predicated on providing a flexible pavement system that is resistant to various types and degrees of failure conditions. Little or no attention has been explicitly devoted to engineering economy in the formulation of the design procedure. Consideration of the total inplace cost of the flexible pavement is generally outside the scope of the structural design method that is selected to provide a flexible pavement that will withstand the deteriorating effects of traffic and envifonment for the service life of the highway.

The purpose of this systems approach to the structural design of asphalt pavements was to develop a practical and realistic method for the optimal selection of the various components that comprise the total cross-section of a flexible pavement. The design model consists of an objective function and nine constraining equations. The total inplace cost is completely described by the objective function,

*Professor and Chairman, Department of Civil Engineering, University of Vermont, Burlington, Vermont.

**Transportation Engineer, Wilbur Smith and Associates, New Haven, Connecticut.

***Mathematician, Department of Mathematics, University of Vermont, Burlington, Vermont. 
Digitized by the Internet Archive in 2011 with funding from

LYRASIS members and Sloan Foundation; Indiana Department of Transportation 
and a minimum-cost solution is obtained for each combination of material costs, design requirements, and environmental conditions. The various constraining equations quantify the boundary conditions to which the design of a flexible pavement is subject. These physical limitations complete the realism of the mathematical model in describing the realworld situation of flexible pavement design. This model is solved by a modified linear programming technique for any flexible pavement design situation.

In developing practical solutions to the design model, optimal flexible pavements are designed for cross-sections without subbase, cross-sections with subbase through shoulders, and cross-sections with subbase and subdrains. The design requirements for the various components are predicated on the design parameters of traffic conditions, soil support values, pavement material characteristics, environmental effects, and pavement performance requirements and on unit costs of pavement components. Substantial cost savings result in the selection of flexible pavement sections by this design procedure. 


\section{INTRODUCTION}

The primary objective of highway pavement design is to provide an acceptable roadway surface that can withstand the deteriorating effects of traffic and environment for the service life of the facility. In addition, the pavement structure must adequately serve the demands of the road users at an acceptable level of performance. A properly designed, constructed, and maintained pavement is a major factor in providing economical, efficient, safe, convenient, and comfortable highway travel.

Although several design techniques are available for determining reasonable thicknesses of flexible pavements to satisfy the specified design parameters, no present method explicitly considers an optimization of flexible pavement components to minimize the total in-place cost of the pavement system. Of course, this cost minimization must be realized within the boundary constraints imposed by the selected values of the design parameters. The purpose of this system analysis was to develop a practical and realistic method for the structural design of asphalt pavements in accordance with sound engineering economy.

The objective of flexihle pavement design in this investigation is to select the various pavement components so that the total pavement cost is minimized within the limitations of the various design and environmental parameters. Minimum-cost designs are determined for flexible 
pavements to satisfy the demands of traffic and environment on the system of pavement structure and soil support. Therefore, this technique affords a practical and economical solution to the problem of designing flexible pavements.

To substantiate the validity of this optimization approach to the structural design of asphalt pavements, a sensitivity analysis was performed on those parameters which serve as input to the design process. These variables include the various descriptors of material costs, material characteristics, soil support, traffic conditions, and environmental effects.

DESIGN MODEL

A flexible pavement distributes the traffic loads through a system of pavement components to the subgrade. These pavement layers are generally identified as surface, base, and subbase. Several different thickness combinations of the materials comprising the various components may adequately satisfy the structural design of the highway pavement. However, all satisfactory thickness arrangements may not provide an economical solution to the engineering problem of pavement design. In general, only one pavement structure is an optimal selection of the flexible pavement components for the designated design conditions. 


\section{Concept}

The concept for this optimal structural design of asphalt pavements is summarized by the logic diagram in Figure 1. The structural requirements of flexible pavements are predicated on an estimated number of equivalent $18-k i p$ single-axle load repetitions and on an appropriate measure of the soil support afforded by the subgrade. The elements of pavement performance and environment are also incorporated as initial and terminal serviceabilities and regional factor, respectively. The combined effect of traffic loading, soil support, pavement performance, and environment is denoted as a structural number ( $\mathrm{SN}$ ) according to the interim design guide of the American Association of State Highway Officials for flexible pavements. ${ }^{1}$ Pavement component thicknesses are then selected to reproduce the specified structural number by a linear combination of layer thickness times its coefficient of relative strength. A minimum pavement thickness is equal to the summation of the component thicknesses.

Consideration of significant environmental factors, such as depth of frost penetration and reduced subgrade strength, provides additional controls on the selection of a minimum pavement thickness. This design procedure specifies a minimum pavement thickness ( $\mathrm{T}_{\mathrm{min}}$ ) to account for various influencing environmental considerations is based on two determinations: (1) a reduced subgrade strength design procedure that requires a selected design wheel load and a specified soil support value and (2) the depth of 
frost penetration. The largest minimum thickness value based on the structural requirement, reduced subgrade strength condition, or frost penetration becomes the design requirement.

To account for varying design practices, several types of pavement cross-sections are available as possible alternatives in this procedure for designing flexible pavements. These arrangements include cross-sections without subbase, cross-sections with subbase through shoulder, and cross-sections with subbase and subdrain. Finally, the unit costs of the pavement components are specified to permit the design of an acceptable pavement structure for the least cost. This cost-effectivness approach provides both an optimal and a practical solution to the problem of flexible pavement design.

In a real sense, the minimum thicknesses represent design constraints and not design objectives. The design objective is to produce a flexible pavement system at the least total cost within the specified boundary conditions. The in-place unit costs of the component materials depend on the locale in which the flexible pavement is to be constructed. In addition to the traffic loading, soil support, pavement performance, and environment constraints, practical limitations on layer thicknesses are specified in concurrence with present highway construction practices. 


\section{Design Parameters}

The design parameters represent the various measures of traffic conditions, soil support, pavement material properties, environmental effects, and pavement performance requirements. The results of these evaluations provide the summary quantities that are necessary for the optimal design of flexible pavements.

The initial measure of the stability of the subgrade soil is determined by the standard California bearing ratio test. This soil strength is then translated into the soil support value (SSV) as defined by the American Association of State Highway Officials. ${ }^{1}$ In this study the following equation was developed to relate soil support values to California bearing ratio measures:

$$
S S V=4.90 \log _{10}(C B R)
$$

where $\quad$ SSV = soil support value and

$$
\mathrm{CBR}=\text { California bearing ratio. }
$$

The traffic conditions are expressed as the number of 18-kip single-axle load repetitions for the service life of the pavement. These load applications are estimated from an evaluation of the following formula:

$$
W=365(\mathrm{TF})(\mathrm{DP})
$$

where

$$
\begin{aligned}
W= & \text { total number of equivalent } 18-k i p \text { single-axle } \\
& \text { load repetitions during the pavement design } \\
& \text { period, } \\
\mathrm{TF}= & \text { truck factor }(18-\mathrm{kip} \text { single-axle load } \\
& \text { applications per day), and } \\
\mathrm{DP}= & \text { design period (years). }
\end{aligned}
$$


To develop a measure of the truck factor, a correlation was derived between the number of 18 -kip single-axle load applications and the percentages of various truck types in the traffic streams. The following expression was obtained from loadometer data collected on typical state highways:

$$
\begin{aligned}
T F & =\left[\frac{\left(\mathrm{ADT}_{1}\right)+\left(\mathrm{ADT}_{2}\right)}{4}\right] x \\
& {\left[\frac{11.7(\mathrm{TR})(\mathrm{LU})+0.83(\mathrm{TR})(\mathrm{LU})(\mathrm{CT})}{10,000}\right] }
\end{aligned}
$$

where

$$
\begin{aligned}
\mathrm{TF}= & \text { truck factor (18-kip single-axle load } \\
& \text { applications per day), } \\
\mathrm{ADT}_{1}= & \text { average daily traffic volume at the start of } \\
& \text { the design period (vehicles per day in both } \\
& \text { directions), } \\
\mathrm{ADT}_{2}= & \text { average daily traffic volume at the end of } \\
& \text { the design period (vehicles per day in both } \\
& \text { directions), } \\
\mathrm{TR}= & \text { percentage of all trucks, } \\
\mathrm{CT}= & \text { percentage of combination trucks, and } \\
\mathrm{LU}= & \text { truck lane usage factor (1.0, } 0.9 \text {, and } 0.8 \\
& \text { for two-, four }-, \text { and six-lane highways, } \\
& \text { respectively). }
\end{aligned}
$$

The various measures of traffic conditions, soil support, environmental effects, and pavement performance requirements are now combined into a single design parameter defined as the structural number (SN). Two nomographs have been prepared by the American Association of State Highway officials to quantify this structural requirement. ${ }^{1}$ However, the following equation was developed from these nomographs to use in the computer program for this design procedure: 


$$
\begin{aligned}
\log _{10}(W) & =9.36 \log _{10}[(\mathrm{SN})+1]-0.20 \\
& \left.+\log _{10}\left[\frac{(\mathrm{CO})-(\mathrm{P})}{(\mathrm{CO})-1.5}\right]\right] \\
& {\left[0.40+\frac{1094}{[(\mathrm{SN})+1]^{5.19}}\right] } \\
& +0.37756[(\mathrm{SSV})-3.0]-0.97 \log _{10}
\end{aligned}
$$

where

$$
\begin{aligned}
W= & \text { total number of equivalent } 18 \text {-kip single-axle } \\
& \text { load repetitions during the pavement design } \\
& \text { period, } \\
\mathrm{SN}= & \text { structural number, } \\
\mathrm{CO}= & 4.2 \text { initial pavement serviceability index, } \\
\mathrm{P}= & \text { terminal pavement serviceability index, } \\
\mathrm{SSV}= & \text { soil support value, and } \\
\mathrm{RF}= & \text { regional factor. }{ }^{2}
\end{aligned}
$$

The effects of the environment are numerically summarized in the regional factor, and the desired pavement performance is specified by selected values for the initial and terminal pavement serviceability indices. An iterative procedure is used to solve the above equation for the structural number of a particular design situation.

The second consideration of environmental influence is to determine a minimum thickness as a design against the detrimental effects of frost action and the loss of subgrade strength in the spring break-up period. Design charts that were developed by L. D. Hicks provide correlations between bearing ratio and between pavement thickness and bearing 
capacity. ${ }^{4}$ Adverse subgrade conditions are represented by using a four-day soaked value for the selected California bearing ratio. The following relationships were prepared from these design charts for 9-kip and 10-kip wheel loads, respectively:

$$
\begin{aligned}
& T_{\min \cdot(9)}=4.723+\frac{61.037}{(C B R)^{1.05}}-45.18 \mathrm{e}^{-(C B R)} \\
& T_{\min \cdot(10)}=4.423+\frac{52.706}{(C B R)^{0.90}}-19.884 \mathrm{e}^{-(C B R)}
\end{aligned}
$$

where $T_{\min .(9)}=$ minimum pavement thickness for 9-kip design wheel load (inches),

$\mathrm{T}_{\min (10)}=$ minimum pavement thickness for $10-\mathrm{kip}$ $C B R=$ California bearing ratio for reduced strength conditions.

The 10-kip wheel load is considered satisfactory for the design of primary highways, while the 9-kip wheel load is applicable for flexible pavements on secondary routes. In the computer input for this design model, the highway engineer specifies the design wheel load for either a primary or a secondary highway. This minimum-thickness determination accounts for environmental effects by highway classification and provides another realistic constraint in selecting optimal flexible pavement sections.

The depth of frost penetration was incorporated into the design model as the third evaluation of environmental deterioration on pavement performance. This consideration made the design model more general by allowing the pavement 
designer to provide complete protection against freezing in the subgrade. The depth of frost penetration is calculated from the freezing index according to the following relationship:

$$
\log Q Z=0.2218+0.4771 \log \mathrm{FI}
$$

where $Q Z=$ depth of frost penetration (inches), and

$F I=$ freezing index (degree days). 5

The characteristics of each pavement material are described by the in-place density and the coefficient of relative strength. These values depend on the local materials that are used in the construction of flexible pavements. The evaluation of the pavement material characteristics permits the application of the design model for the prevailing construction practices.

The above descriptions numerically define the various design components of the flexible pavement system. Although the selected equations provide reasonable evaluations of these parameters, other expressions can be used to satisfy local design conditions.

\section{Design Sections}

Because reasonable variations exist in the design of highway elements, three acceptable cross-sections were selected for two-lane and divided multi-lane highways to provide several alternative designs in the model. These arrangements include the following distinct designs: 
1. Cross-sections without subbase $\left(\mathrm{S}_{1}\right)$,

2. Cross-sections with subbase $\left(\mathrm{S}_{2}\right)$

a. Extended through the shoulders for twolane highways and

b. Extended through the right shoulder with subdrain under the left shoulder for divided multi-lane highways, and

3. Cross-sections with subbase and subdrains under both shoulders $\left(\mathrm{S}_{3}\right)$.

Typical details of these cross-sections have been illustrated in a previous publication dealing with this approach to the structural design of asphalt pavements. ${ }^{3}$

of course, other cross-sectional arrangements may be incorporated into this design model. Because each section represents a different design, an objective function is required for each cross-section to permit the optimal selection of flexible pavement sections. The best design is then that cross-section which minimizes the total pavement cost for the specified design parameters.

\section{Optimization Mode1}

The optimal design of flexible pavement sections is depicted by the following objective functions for the three different design sections:

1. Cross-sections without subbase;

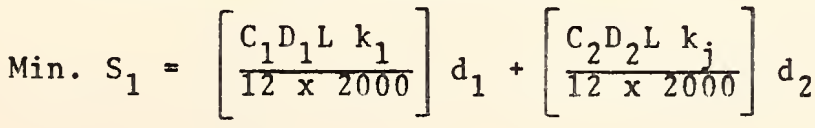

$$
\begin{aligned}
& +\left[\frac{C_{3} D_{3} k_{j}}{12 \times 2000}\right] d_{3}+E_{\ell}+H_{\ell}
\end{aligned}
$$


2. Cross-sections with subbase through shoulders;

$$
\text { Min. } \begin{aligned}
S_{2} & =\left[\frac{C_{1} D_{1} k_{1}}{12 \times 2000}+\frac{C_{4} A}{12 \times 27}\right] d_{1} \\
& +\left[\frac{C_{2} D_{2} k_{j}}{12 \times 2000}+\frac{C_{4} A}{12 \times 27}\right] d_{2} \\
& +\left[\frac{C_{3} D_{3} L k_{j}}{12 \times 2000}+\frac{C_{4} A}{12 \times 27}\right] d_{3} \\
& +\left[\frac{C_{4}(L+A)}{12 \times 27}\right] d_{4}+E_{\ell}+H_{\ell}+M_{\ell}-Y_{\ell}
\end{aligned}
$$

3. Cross-sections with subbase and subdrains;

$$
\begin{aligned}
& \text { Min. } S_{3}=\left[\frac{C_{1} D_{1} L k_{1}}{12 \times 2000}+\frac{C_{4} B}{12 \times 27}\right] d_{1} \\
& +\left[\frac{C_{2} D_{2} k_{j}}{12 \times 2000}+\frac{C_{4} B}{12 \times 27}\right] d_{2} \\
& +\left[\frac{C_{3} D_{3} k_{j}}{12 \times 2000}+\frac{C_{4} B}{12 \times 27}\right] d_{3} \\
& +\left[\frac{C_{4}(L+B)}{12 \times 27}\right] d_{4}+E_{\ell}+H_{\ell}+N-Z_{\ell}
\end{aligned}
$$

where

$$
\begin{aligned}
S= & \text { total cost of pavement system (dollars per } \\
& \text { longitudinal foot), } \\
C_{i}= & \text { unit cost of material ' } i \text { ' (dollars per ton } \\
& \text { for materials } 1,2,3, t \text {, and } 8 \text {, dollars } \\
& \text { per cubic yard for materials } 4 \text { and } 6 \text {, and } \\
& \text { dollars per foot for material } 7 \text { ), } \\
D_{i}= & \text { density of material ' } i \text { ' (pounds per cubic } \\
& \text { foot), }
\end{aligned}
$$



$\mathrm{L}=$ pavement width (24 ft for two-lane and one-way section of divided four-lane highways and $36 \mathrm{ft}$. for one-way section of divided six-lane highways),
$d_{i}=$ thickness of material ' $i$ ' (inches),
$i=1$ for bituminous surface, 2 for stabilized base, 3 for compacted aggregate base, 4 for granular subbase, 5 for bituminous shoulder surface, 6 for subdrain granular fill, 7 for subdrain pipe, and 8 for wearing surface,
$k_{j}=$ adjustment factor for increase in width of pavement layers;
$k_{1}=1.00$ for first layer,
$k_{2}^{1}=1.04$ for second layer,
$k_{3}^{2}=1.08$ for third layer, and
$\mathrm{k}_{4}^{3}=1.12$ for fourth layer,
$E_{\ell}=$ cost of shoulder (dollars per longitudinal foot),

For two-lane highways:

$$
\begin{aligned}
E_{1} & =20 \times 3.0\left[\frac{{ }_{5} D_{5}}{12 \times 2000}\right] \\
& +31 \times 6.0\left[\frac{C_{3} D_{3}}{12 \times 2000}\right]
\end{aligned}
$$

For divided multi-lane highways;

$$
\begin{aligned}
E_{2} & =14 \times 3.0\left[\frac{C_{5} D_{5}}{12 \times 2000}\right] \\
& +19.75 \times 6.0\left[\frac{C_{3} D_{3}}{12 \times 2000}\right]
\end{aligned}
$$

$\mathrm{H}_{\ell}=$ adjustment for the additional cost of the wearing surface for two-lane and four-lane highways ;

$$
\mathrm{H}_{1}=\frac{\left(C_{8}-C_{1}\right)}{12 \times 2000} D_{1} \times\left(\frac{90}{110}\right) \times 24
$$

for six-lane highways;

$$
\mathrm{H}_{2}=\frac{\left(\mathrm{C}_{8}-\mathrm{C}_{1}\right)}{12 \times 2000} \mathrm{D}_{1} \times\left(\frac{90}{110}\right) \times 240
$$


$A_{\ell}=$ width of shoulder subbase for an embankment slope of $6: 1$ (feet),

For two-lane highways;

$A_{1}=22+\frac{2\left(d_{1}+d_{2}+d_{3}\right)}{3}$

For divided multi-lane highways;

$$
A_{2}=14.375+\frac{\left(d_{1}+d_{2}+d_{3}\right)}{3}
$$

$B_{\ell}=$ adjusted width of shoulder subbase when subdrains are provided (feet),

For two-lane highways:

$\mathrm{B}_{1}=5.0$

For divided multi-lane highways;

$B_{2}=5.875$

$M_{\ell}=$ cost of subdrain when used under median shoulder only (dollars per longitudinal foot),

For two-lane highways;

$M_{1}=0.0$

For divided multi-lane highways;

$M_{2}=1.1\left(0.075 C_{6}+C_{7}\right)$

$N=$ cost of subdrains under both shoulders (dollars per longitudinal foot),

For all highways;

$N=2 \times 1.1\left(0.075 C_{6}+C_{7}\right)$

$\mathrm{Y}_{\ell}=$ adjustment for the amount of subbase material replaced by the shoulder surface and base (dollars per longitudinal foot), and

For two-lane highways;

$Y_{1}=\frac{258 \times C_{4}}{12 \times 27}$ 
For divided multi-lane highways;

$$
Y_{2}=\frac{162 \times C_{4}}{12 \times 27}
$$

$z_{\ell}=$ adjustment for the amount of subbase material added above the level of the pavement subbase under the shoulders;

For two-lane highways;

$z_{1}=\frac{50 \times C_{4}}{12 \times 27}$

For divided multi-lane highways;

$$
z_{2}=\frac{60 \times C_{4}}{12 \times 27}
$$

Thus, the objective of this optimal selection of flexible pavement components is to minimize the total cost of the pavement system. The various material and layer notations of the design model are graphically described in the figures which illustrate the design sections.

To quantify the boundary conditions to which the optimal design of the flexible pavement components is subject, the following constraint equations are necessary to complete the realism of this design model.

1. The selection of layer thicknesses must satisfy the structural number requirement.

$$
a_{1} d_{1}+a_{2} d_{2}+a_{3} d_{3}+a_{4} d_{4} \geq S N
$$

where

$$
\begin{aligned}
& a_{i}=\text { coefficient of relative strength of material } \\
& \mathrm{SN}=\text { structural number for design. }
\end{aligned}
$$


2. The total thickness of the flexible pavement must be at least equal to the minimum thickness which is required by an influencing environmental consideration.

$$
\mathrm{d}_{1}+\mathrm{d}_{2}+\mathrm{d}_{3}+\mathrm{d}_{4} \geq \mathrm{T}_{\text {min }}
$$

where $\quad T_{\text {min }}=$ total minimum thickness of flexible pavement to satisfy environmental conditions.

The remaining constraining equations are required to account for the physical limitations inherent in the construction of the various layers of a flexible pavement. The following seven relationships complete the mathematical representation of the concept for the optimal selection of flexible pavement components.

3. The bituminous surface course of a primary highway is at least 3.0 in. in thickness.

$$
d_{1} \geq 3.0
$$

4. If a stabilized base is selected for the pavement system, the minimum thickness is 4.0 in.

$$
\mathrm{d}_{2}=0 \text { or } \geq 4.0
$$

5. If a compacted aggregate base is included in the flexible pavement, a minimum thickness of 4.0 is necessary for construction purposes.

$$
\mathrm{d}_{3}=0 \text { or } \geq 4.0
$$

6. If a granular subbase is specified from the optimal selection, at least a 4.0-in. layer is required.

$$
\mathrm{d}_{4}=0 \text { or } \geq 4.0
$$


7. Because rutting and shoving of the pavement surface may result under high load repetitions for excessive thicknesses of bituminous mixtures, the maximum thickness of the bituminous surface is $10.0 \mathrm{in}$.

$$
\mathrm{d}_{1} \leq 10.0
$$

8. The maximum thickness of the stabilized base is established at 10.0 in. because of large vertical deformations that may result in this base course if excessive thicknesses of bituminous mixtures are used.

$$
\mathrm{d}_{2} \leq 10.0
$$

9. An upper 1 imit of 20.0 in. is set for the thickness of the granular subbase to conform with present construction practice.

$$
\mathrm{d}_{4} \leq 20.0
$$

The solution to this design model has been described in a previous publication. ${ }^{3}$ Several design examples were also included in that publication to describe the contents of the computer output and to illustrate the cost-effectiveness evaluation that is permitted in this approach to the structural design of flexible pavements. However, an actual pavement design is presented as Example 1 for conditions that are typical for the United States of America. 


\section{SENSITIVITY ANALYSIS}

To test the response of this flexible pavement model to changing design conditions, a sensitivity analysis was performed to quantify the total in-place cost changes that result from significant variations in the input values of the various design parameters. Significant variations of the design and environmental parameters were considered as the average value plus 20 percent of that value and as the average value minus 20 percent of that value. The various averages were selected to be indicative of mid-values for highway design conditions throughout the United States of America. This sensitivity analysis tested the significance of input parameters for material costs, material characteristics, soil support, traffic conditions, and environment.

\section{Unit Cost and Density of Material}

Because the unit cost of material and the density of material are each linearly related to the total cost of the flexible pavement system in the objective function, a percentage sensitivity analysis provides identical results on the variability of both material costs and material characteristics. A change of plus and minus 20 percent about the selected average values for either the unit cost of materials or the density of these pavement materials produces a variation from 0.8 to 15.1 percent in the total in-place cost of the flexible pavements with an average change of 6.4 
percent. If the direction of parameter change is considered as either increasing or decreasing, then these two design categories operate in inverse manner on the total cost of the flexible pavement system. Reasonable knowledge of these cost and material parameters is required if sound engineering economy is to be achieved in this technique for the structural design of asphalt pavements.

\section{Coefficient of Relative Strength of Material}

Another material characteristic evaluated in this sensitivity analysis is the coefficient of relative strength for each possible pavement material considered in the design process. Less sensitivity is observed in this design parameter as a range of 0.0 to 2.4 percent with an average value of 1.3 percent is produced in the total pavement cost for a plus and a minus variation of 20 percent in the various coefficients of relative strength. Therefore, little penalty in economics accrues from the lack of precise determination of this material characteristic.

\section{California Bearing Ratio Value}

The soil support of the existing subgrade is represented by the California bearing ratio in this optimal design procedure for both the structural requirement and the condition of reduced subgrade strength due to adverse environmental conditions. An average sensitivity of 3.1 percent variation in total cost of the pavement system with 
a range between 1.0 and 4.7 percent is indicative of a 20 percent change in CBR values about the designated design average. Some care must be exercised in the determination of the soil support as an input to this method of designing flexible pavements.

Percentage of Combination Trucks

In this portion of the sensitivity analysis a variation of 50 percent above and 50 percent below the average was used to ascertain the significance of the percentage of truck combinations in altering the cost of the flexible pavement structure. This large variation in commercial vehicles is reflected by almost insignificant changes in the minimalcost pavement design. An average change of 1.1 percent with a range of 0.0 to 4.1 percent is related to variations of plus 50 percent and minus 50 percent about the average percentage of combination trucks.

Design Period and Number of Equivalent Load Repetitions

In addition to the percentage of truck combinations, the design period and the number of equivalent load repetitions reflect the traffic conditions to which the flexible pavement is subjected over the service life. Because the number of equivalent load repetitions is positively and linearly related to the design period, identical sensitivities are evident for these two design parameters. Changes of plus 20 percent and minus 20 percent from the average value 
account for only an average total cost variation of 0.9 percent and a range of 0.0 to 4.2 percent in the minimum cost. Therefore, the refinement of traffic conditions affords little enhancement of design sophistication in this procedure for optimizing the structural design of flexible pavements.

\section{Freezing Index}

The freezing index is inputed for determining the depth of frost penetration in this design model. A reasonably significant sensitivity is evident with a plus 20 -percent and a minus 20 -percent variation about the average value of 250 degree days producing an average change of 4.8 percent with a range of 1.2 to 6.9 percent in the total in-place cost of the flexible pavement system. This measure of environmental conditions should be carefully evaluated because, in addition to the inherent sensitivity, this design parameter becomes controlling in terms of pavement thickness for those highway locations with severe winters.

\section{SUMMARY}

The development of this procedure for the design of flexible pavements provides a direct determination of the optimal design. The resultant design model involves the selection of that pavement cross-section which minimizes the total cost of the pavement system for the selected unit costs of the pavement materials, for the specified values of the various design and environmental parameters, and for 
the prevailing construction practices. Each flexible pavement section fulfills the design objectives for the least total in-place cost. Therefore, this cost-effectiveness approach provides an optimal, practical, and economical solution to the problem of designing flexible pavements.

As a result of the sensitivity analysis of this design model for flexible pavements, unit cost of material, density of material, California bearing ratio value, and freezing index are those design and environmental variables that significantly impact on the design process. Therefore, these parameters must be selected with care to produce the real economies that accrue from design methods based on the systems approach. On the other hand, significant variations in the coefficient of relative strength of material, percentage of combination trucks, design period, and number of equivalent load repetitions do not appreciably alter the final pavement design in terms of the total in-place cost. These design parameters satisfy the generic function of sizing in the design process.

Although many accepted design procedures are available for numerous engineering problems, few techniques permit a direct determination of the optimal design. In general, these existing design methods only satisfy codes or regulatory constraints that apply to selected components of the design system. However, many design algorithms can be modified to 
to permit the optimal design of an engineering system by the application of modern optimization routines. The combination of these mathematical techniques with existing design procedures places engineering design on the threshold of a new era.

\section{BIBL IOGRAPHY}

1. AASHO Committee on Design, AASHO Interim Guide for the Design of Flexible Pavement Structures, American Association of State Highway Officials, 1961.

2. Buick, T. R., "Analysis and Synthesis of Highway Pavement Design," a Thesis submitted to Purdue University for the degree of Master of Science in Civil Engineering, June 1968.

3. Hejal, S. S., S. R. Yoder, and J. C. Oppenlander, "Optimal Design of Flexible Pavement Section," Highway Research Record, Highway Research Board, Number 337, 1970 .

4. Hicks, L. D., "Structural Design of Flexible Pavements in North Carolina," Proceedings, International Conference on the Structural Design of Asphalt Pavements, University of Michigan, August 1962.

5. Yoder, E. J., Principles of Pavement Design, John Wiley \& Sons, Inc., New York, 1959 . 


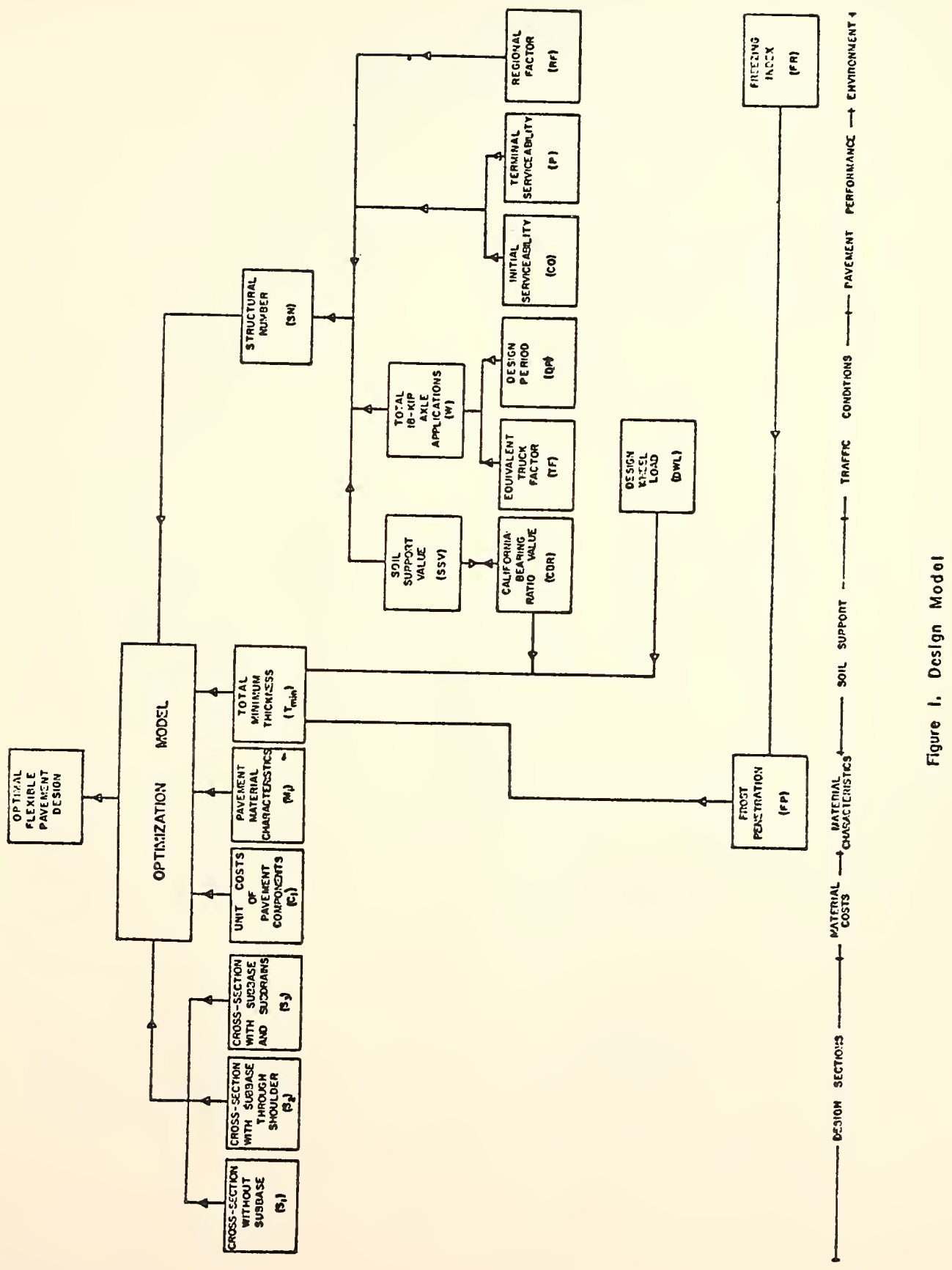


EXAMPLE 1

DESIGN OF FLEXIBLE PAVEMENT

FOR PRIMARY HIGHWAYS

Design Data

Number of 1 anes

CBR

Average daily traffic 1971

Average daily traffic 1991

Design period

Percent trucks

Percent multiple units

Design wheel load

Regional factor

Pavement terminal serviceability

Freezing index

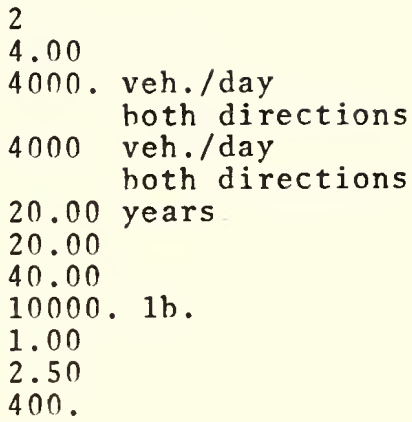

Materials Specifications

Cost

Density

Bitumin. wearing surface

$10.00 \$ /$ ton

145. $1 \mathrm{~b} / \mathrm{ft} 3$

Bituminous surface base

Stabilized hase

$9.00 \$ /$ ton

145. $1 \mathrm{~b} / \mathrm{ft} 3$

$8.00 \$ /$ ton

145. $1 \mathrm{~b} / \mathrm{ft} 3$

Compacted aggregate base

4.00

$\$ /$ ton

$3.00 \$ / y d z$

Granular subbase

$8.00 \$ /$ ton

Shoulder surface

$5.00 \$ / y d 3$

135. $1 \mathrm{~h} / \mathrm{ft}$

Aggregate for subdrain

$0.71 \$ / \mathrm{ft}$

145. $1 \mathrm{~b} / \mathrm{ft} 3$

Pipes for subdrain

Solution

Number of lanes

Percent multiple units

Structural number

Total thickness

Truck factor

2

40.00

4.15

29.1 inches

$18 \mathrm{n} .18 \mathrm{k} / \mathrm{day}$

Optimal Solution

Cross-section without subbase

Bituminous surface

Stabilized base

Compacted aggregate hase

Granular subbase
Thickness

$3 . n$ inches

0.0 inches

26.1 inches

0.0 inches 
Alternative Solution (suboptimal)

Cross-section with subdrain

Bituminous surface

Stabilized base

Compacted aggregate base

Granular subbase

Cost

Alternative Solution (suboptimal)

Cross-section with subbase through shoulder

Bituminous surface

Stabilized base

Compacted aggregate base

Granular subbase

Cost
Thickness

5.9 inches

4.0 inches

4.0 inches

15.2 inches

$28.69 \$$ per long. ft.
Thickness

8.7 inches

0.0 inches

4.0 inches

16.3 inches

$33.22 \$$ per long. ft. 

